\title{
Comment on "Methadone Dose Adjustments, Plasma R-Methadone Levels and Therapeutic Outcome of Heroin Users: A Randomized Clinical Trial"
}

\author{
Ernesto de Bernardis \\ Addiction Service SerT of Lentini, Lentini, Italy
}

\section{Dear Editor,}

Mannaioni et al. [1], in their recent randomised clinical trial on methadone dosing adjusted according to serum $\mathrm{R}$-methadone levels, chose a target window of $80-250 \mathrm{ng} / \mathrm{mL}$ R-methadone based on results by Eap et al. [2].

Eap's paper, though, clearly indicates the best threshold for therapeutic response at R-methadone levels greater than $250 \mathrm{ng} / \mathrm{mL}$, suggesting the need for even higher levels in resistant subjects.

More recently, Meini et al. [3], also acknowledged by Mannaioni et al. [1], confirmed Eap's results, showing in their sample of methadone-treated patients the presence of a $\mathrm{R}$-methadone threshold of $200 \mathrm{ng} / \mathrm{mL}$ for absence of heroin use, and
$250 \mathrm{ng} / \mathrm{mL}$ for absence of craving. According to Meini's published data on graph, more than $40 \%$ of the heroin-using patients in his sample had trough R-methadone levels falling between 80 and $250 \mathrm{ng} / \mathrm{mL}$.

Thus, it is conceivable that the target therapeutic window chosen by Mannaioni et al. [1], starting at less than one third of the optimal threshold level and ending just at it, might have been too low to deliver a clear effect in comparison with controls, both on retention in treatment and on use of illegal psychoactive substances.

It would be very interesting if the Authors could discuss further on the rationale for their choice to use target levels much lower than those adviced by Eap et al. [2] and Meini et al. [3], and known to be associated with a clinically relevant use of street heroin.

\section{Disclosure Statement}

As the sole Author, I hereby certify that I have no conflict of interests.

\section{Funding Sources Statement}

No funding whatsoever were received for this Letter.

\section{References}

1 Mannaioni G, Lanzi C, Lotti M, Galli V, Totti A, Pacileo I, Sili M, Pracucci C, Dilaghi A, Bertieri L, Quaranta M, et al: Methadone dose adjustments, plasma R-methadone levels and therapeutic outcome of heroin users: a randomized clinical trial. Eur Addict Res 2018; 24:9-18.
Eap CB, Bourquin M, Martin J, Spagnoli J, Livoti S, Powell K, Baumann P, Deglon J: Plasma concentrations of the enantiomers of methadone and therapeutic response in methadone maintenance treatment. Drug Alcohol Depend 2000;61:47-54.
Meini M, Moncini M, Daini L, Giarratana T, Scaramelli D, Chericoni S, Stefanelli F, Rucci P: Relationship between plasma concentrations of the l-enantiomer of methadone and response to methadone maintenance treatment. Eur J Pharmacol 2015;760: $1-6$.

\section{KARGER}

(C) 2018 S. Karger AG, Basel

E-Mail karger@karger.com

www.karger.com/ear
Ernesto de Bernardis, MD

Addiction Service SerT of Lentin

Via Ospedale 18, ASP Siracusa

IT-96016 Lentini (Italy)

E-Mail ernesto@ debernardis.it 